\title{
Editorial
}

\section{The price of sunlight!}

The number of conferences, seminars and other 'events' involving issues of compliance and governance could lead one to the conclusion that it is only recently that such issues have been 'discovered' or at least come to be considered important. A particularly dramatic aspect has been the placing of enhanced obligations on those who are, by virtue of their position or actions, responsible for others. The notion of putting those in the way of business in the 'front line' in 'policing' crime and corruption is nothing new. Indeed, there were associations and initiatives in the 19th century concerned with promoting integrity in business and emphasising the 'obligation' on those involved in business to ensure the maintenance of proper standards. In the early 1960s, the US Securities and Exchange Commission initiated a programme designed to turn certifying accountants and those with managerial supervisory authority into 'informants' against fraud and abuse. This was done, with some degree of success, by imposing legal and regulatory liability on those who 'controlled' the activities of others and through attenuated notions of 'aiding and abetting'. In certain circumstances employers are responsible for the frauds and misconduct of their subordinates, unless they can show that they took appropriate steps to ensure as far as is reasonable, that the misconduct in question did not occur. Indeed, it might well come as a surprise to many that in-house procedures and codes of conduct were in fact so developed by the 1970s in the USA, UK and a number of other jurisdictions.

Placing an obligation to take affirmative action to 'blow the whistle' on auditors has over the last decade become if not common place, more or less accepted. Extending such an obligation to others is rather more controversial, but has in practice been achieved, in some measure, through legislation and regulations aimed at laundering the proceeds of serious crime. In most jurisdictions, once suspicion arises, to escape liability for taking any further action in regard to the property in question, a confidential report must be made to the authorities. In addition to 'suspicion-based reporting' obligations, in many countries specific and affirmative obligations are cast upon certain professionals, such as financial intermediaries, lawyers, accountants and fiscal agents to report suspicions irrespective of whether they are involved in a particular transaction or not. Forms of liability, ranging across the legal spectrum, have also been devised, albeit rarely applied outside the USA, for various manifestations of what might be described as 'control' over the employee or associate responsible for actual misconduct. Areas of liability have developed, particularly in the civil and 'administrative' law based largely on the possession of knowledge or the attribution of knowledge and a given, actual or deduced state of mind. Most systems of law have also given rather more protection, at least in form if not substance, to those who whether under an obligation or not actually 'blow the whistle'. On the other hand, few have been prepared to venture quite as far as the USA in positively rewarding — by bounties and the like - informers against misconduct.

Exercising the responsibilities of stewardship — in the broadest sense of the concept - obviously requires at least access to pertinent information on a timely basis. After all, while the 'badge of fraud' might today be rather more connivance than 
silence, it is the case that the maintenance of a fraud is more difficult in the glare of 'sunlight'. Having said this, the old adage that 'you can never have too much information' is of questionable validity in the modern world, when in almost every walk of life we are swamped by information or at least access to information, that is invariably in form, quantity and character well beyond our abilities to process and effectively utilise. Apart from the costs, both direct and indirect, of 'creating' information, to leave it under or ineffectively utilised, raises profound issues as to the competence and, indeed, integrity of the system that demands it. Of course, much depends upon the purposes of the organisation in requiring information. Very few authorities have the ability to act on a real time basis on, for example, information filed in compliance with financial and currency reporting obligations. However, the information - once in the system - does allow for the 'reconstruction' of transactions and may, with the application of intelligenceorientated procedures, provide useful assistance. It must also be remembered that the very act of, or rather requirement for, disclosure may constitute a hurdle to those who wish to engage in undesirable activity. Purported compliance and evasion will both involve additional costs and risks.

There is, however, a danger that the accumulation of information, and even its refinement into what might amount to intelligence, is seen as an end in itself with all the institutional implications that this may have for the organisation concerned and those who deal with it. It has long been recognised that the financial community and their regulators might well find considerable benefit in a coordinated, if not 'centralised', data network carrying regulatory and disciplinary information. Indeed, attempts were made through the Commonwealth Secretariat by British Commonwealth Governments to set up such a system 20 years ago. The new Global Regulatory Information Data- base (GRID) has over 20,000 sources and databases. While almost all the information is 'publicly available' the scope and depth of this network provides the banks that sponsored it with a powerful tool. The various procedures operated on the individual databases of banks and other financial institutions are becoming increasingly sophisticated and intelligent. While there are legitimate concerns as to the reliability and integrity of information, concerns based purely on issues of privacy appear to be of little consequence, given the very real burden of risk imposed on any financial intermediaries. Sarbanes-Oxley imposes extensive new reporting requirements, most particularly the certification of internal controls. The attestation regulations under section 404 impose significant new reporting requirements, and the audit of such internal controls under the Public Accounting Oversight Board regulations will generate a virtual deluge of information. While public companies do not have an expectation of privacy, these regulations are part and parcel of the generation of information in the wake of Enron and 9/11 - an example of the latter being the extensive new bank reporting requirements under the Patriot Act. But whether such extensive new costs incurred by public companies for compliance will do more than serve as a boon to accounting firms remains to be seen. Worldcom is said to have enjoyed extremely robust internal controls.

A recent case before the English High Court (Amalgamated Metal Trading Ltd v. City of London Police [2003] 4 All ER 1225), emphasised the responsibility of the financial institution in question to make a commercial decision on the basis of its assessment of the commercial risk. There have now been a series of cases, from both sides of the Atlantic, in which the courts have shown a sensible reluctance to intervene in decisions, which are by their nature commercial. Thus, the business judgement rule remains intact despite the decision in the Disney case 
involving Michael Ovitz's compensation. Despite Sarbanes-Oxley, compensation and nominating committees will continue to enjoy wide latitude in their decision-making. There is also an argument that, if the board of directors is in possession of information regarding financial reporting it may approve certain alternate accounting treatments.

While there are those who are increasingly concerned about the cost/benefit of additional disclosure and reporting, particularly in the context raised in this editorial comment, the discussion so far has largely been about financial costs. It has rarely focused on the wider issues and the impact of enhancing disclosure-orientated obligations on the allocation and extent of risk. These are issues that need to be considered with urgency and outside the naive rhetoric stemming from 9/11, Enron and Worldcom.

Professor Barry A. K. Rider 